\title{
Sibling Influences on Risky Behaviors from Adolescence to Young Adulthood: Vertical Socialization or Bidirectional Effects?
}

Shawn D. Whiteman

Alexander C. Jensen PhD

Brigham Young University, alexjensen@byu.edu

Susan M. McHale

Follow this and additional works at: https://scholarsarchive.byu.edu/facpub

Part of the Psychology Commons

\section{Original Publication Citation}

Whiteman, S. D., Jensen, A. C., \& McHale, S. M. (2017). Sibling influence on risk behaviors from adolescence through early adulthood: Vertical socialization or bidirectional effects? New Directions for Child and Adolescent Development, 156, 67-85. doi:10.1002/cad.20197

BYU ScholarsArchive Citation

Whiteman, Shawn D.; Jensen, Alexander C. PhD; and McHale, Susan M., "Sibling Influences on Risky Behaviors from Adolescence to Young Adulthood: Vertical Socialization or Bidirectional Effects?" (2017). Faculty Publications. 3522.

https://scholarsarchive.byu.edu/facpub/3522

This Peer-Reviewed Article is brought to you for free and open access by BYU ScholarsArchive. It has been accepted for inclusion in Faculty Publications by an authorized administrator of BYU ScholarsArchive. For more information, please contact ellen_amatangelo@byu.edu. 


\title{
Sibling Influences on Risky Behaviors from Adolescence to Young Adulthood: Vertical Socialization or Bidirectional Effects?
}

\author{
Shawn D. Whiteman, Alexander C. Jensen, Susan M. McHale
}

\begin{abstract}
This study built on research on sibling influences to assess potential bidirectional effects of older and younger siblings' risky behaviors on one another's risky behaviors; our longitudinal design allowed us to test these effects when siblings were at about the same chronological age, at different points in time. We also tested whether the strength and/or direction of effects of siblings' risky behaviors changed from middle adolescence to young adulthood. Reports of risky behaviors (i.e., deviant behaviors and excessive alcohol use) were provided by firstborn and secondborn siblings from up to 201 families on five occasions spanning 10 years. In general, accounting for known covariates, multilevel models revealed bidirectional sibling effects and some evidence that secondborns' risky behaviors were stronger and more consistent predictors of firstborns' behaviors than the reverse. Sibling influence generally declined with age and sibling effects were not moderated by gender constellation. Findings indicate that both older and younger siblings are important socializers of risk behaviors across adolescence and continue to shape each other's alcohol use into early adulthood. (C) 2017 Wiley Periodicals, Inc.
\end{abstract}


A

ccumulating research documents that older siblings are key socialization agents in promoting their younger siblings' risk behaviors, including delinquency and externalizing problems (Defoe et al., 2013; Slomkowski, Rende, Conger, Simons, \& Conger, 2001), alcohol and other substance use (Low, Shortt, \& Snyder, 2012; Samek, McGue, Keyes, $\&$ Iacono, 2015), and sexual attitudes and behaviors (East, 1998; McHale, Bissell, \& Kim, 2009) during adolescence. Most research on sibling influences, that is, the associations between two siblings' behaviors or characteristics, has tested only vertical—or top-down-models of socialization, with influences flowing from older to younger siblings. This orientation is logical given the age-graded, sometimes hierarchical nature of sibling relationships (Tucker $\&$ Updegraff, 2009) and the developmental progression of risk behaviors (Brown et al., 2008). The question remains, however, as to whether bidirectional associations between siblings emerge during late adolescence as developmental differences between siblings diminish and relationships become more egalitarian (Buhrmester, 1992). Moreover, with some exceptions (Poelen, Scholte, Willemsen, Boomsa, \& Engels, 2007; Trim, Leuthe, $\&$ Chassin, 2006; Whiteman, Zeiders, Killoren, Rodriguez, \& Updegraff, 2014), we know little about whether sibling influences on risk behaviors continue into early adulthood. This oversight is striking because participation in some kinds of risky behaviors, such as alcohol use, peaks during this developmental period (Chen \& Jacobson, 2012; Staff et al., 2010)-at the same time that sibling relationships become more volitional and peer-like (Cicirelli, 1995; Stocker, Lanthier, \& Furman, 1997).

The current study was designed to contribute to the literatures on sibling influences and adjustment across adolescence and young adulthood. We addressed two goals. First, we tested whether sibling influences on youth's and young adults' risky behaviors (specifically, deviant behaviors and excessive alcohol use) were best characterized by vertical or by bidirectional processes. Second, we assessed whether the strength and/or direction of sibling influences changed from middle adolescence into young adulthood. In addressing these aims, we capitalized on a longitudinal design that allowed us to test the effects of the siblings' risky behaviors on youth's and young adults' deviant behaviors and alcohol use when siblings were at about the same chronological age-at different points in time.

\section{Sibling Socialization Processes}

Consistent with early models of parent socialization during adolescence (Smetana, Robinson, \& Rote, 2015), most research on sibling influences is grounded in a vertical socialization perspective. This research emphasizes sibling socialization in the context of social learning and shared activities and focuses almost exclusively on risky behaviors that emerge and escalate during adolescence, including delinquent and deviant behaviors as well as substance use. For example, rooted in Patterson's (1984) seminal work, 
scholars have investigated how adolescent siblings' interactions shape each other's deviant behaviors: Through observation, reinforcement, and extensive opportunities for practice, sibling relationships provide a context for the development of antisocial and coercive behaviors, which in turn, spill over to other social relationships (Bank, Burraston, \& Snyder, 2004; Criss \& Shaw, 2005).

Siblings also may facilitate one another's deviant behaviors when they act as "partners in crime," such as by defying authority figures and engaging together in rule-breaking and other antisocial behaviors. Given their greater autonomy and involvement in the world beyond the family, older siblings are thought to be more likely to instigate these kinds of activities by, for example, providing alcohol and cigarettes and connecting their siblings to older and deviant peers (Rowe \& Gulley, 1992; Windle, 2000). Consistent with these ideas, three recent studies found that older siblings' facilitation mediated the link between adolescent siblings' alcohol and other substance use (McGue \& Iacono, 2009; Samek et al., 2015; Whiteman, Jensen, Mustillo, \& Maggs, 2016). None of these studies, however, tested the alternative direction of effect, i.e., that younger siblings may facilitate older siblings' use. Additionally, siblings may serve as opportunity providers by introducing their brothers and sisters to settings/activities as well as companions who encourage delinquency, including substance use (Conger \& Rueter, 1996; Low et al., 2012; Windle, 2000). In fact, siblings' patterns of use are more strongly correlated when they share friends (Rende, Slomkowski, Lloyd-Richardson, \& Naiura, 2005; Rowe \& Gulley, 1992).

Siblings also may influence one another's risky behaviors by shaping their expectancies about what behaviors are popular or desirable, including through modeling, self-disclosure, and even coaching and encouragement. D'Amico and Fromme (1997), for example, found that younger siblings' perceptions of their older siblings' alcohol use were tied to their own expectancies. Specifically, youth who believed that their siblings were heavy drinkers endorsed weaker negative and stronger positive alcohol expectancies, which in turn were linked to greater likelihood of actual alcohol use. Similarly, Whiteman et al. (2016) found that older siblings' alcohol use shaped their younger siblings' use both through co-use as well as by modifying their expectations. Again, however, possible bidirectional effects were not explored. Other research has shown that modeling processes moderate the associations between siblings' behaviors and youth's externalizing and delinquent (Patterson, 1984; Rowe \& Gulley, 1992; Slomkowski et al., 2001), substance use (Slomkowski, Rende, Novak, Lloyd-Richardson, \& Niaura, 2005; Whiteman, Jensen, \& Maggs, 2013), and sexual (McHale et al., 2009; Whiteman et al., 2014) behaviors. Most of these studies use cross-sectional designs and treat older siblings' behaviors as the predictors of younger siblings' risky behaviors in early adolescence, when risky behaviors begin to emerge, and significant associations are interpreted as evidence of older siblings' influences. The designs of these studies also mean 
that, in addition to their birth-order status, younger siblings are also lower in chronological age. In an effort to address the confound between age and birth order, in the present study we tested the effects of siblings' risky behaviors on deviant behaviors and excessive alcohol use when firstborns and secondborns were at about the same chronological age-at different points in time.

\section{Sibling Socialization Effects Across Adolescence and Young Adulthood}

The focus on a vertical model of sibling socialization is logical given the hierarchical nature of sibling relationships-particularly in childhood and early adolescence when developmental differences between siblings can be sizeable (Tucker \& Updegraff, 2009). During these years, older siblings are typically more cognitively, socially, and physically mature, which endows them with greater power in their sibling relationships (Miller \& Maruyamu, 1976) and more status as sources of advice and support for their younger brothers and sisters (Tucker, Barber, \& Eccles, 1997). Yet, a developmental perspective on sibling relationships suggests that bidirectional influences may become more likely as youth progress through adolescence and transition into adulthood. Indeed, cross-sectional work revealed that sibling relationships were more egalitarian in later as compared to earlier adolescence (Buhrmester, 1992; Buhrmester \& Furman, 1990). This pattern implies that younger siblings may become more influential as socialization agents for their older sisters and brothers across adolescence and in early adulthood, as developmental differences between them diminish.

Also largely unknown is whether and how younger siblings influence their older siblings' risk behaviors after both have already begun to engage in these behaviors. Given the age grading of risky behaviors (Brown et al., 2008), older siblings will likely be the first to engage in behaviors such as alcohol use, and thus have more influence on younger siblings' initiation of such risky behaviors. After the onset of risky behaviors by both siblings, however, bidirectional influences may be more likely. For example, in contrast to some kinds of problem behaviors, alcohol use tends to increase in young adulthood (Chen \& Jacobson, 2012; Staff et al., 2010), and siblings' mutual alcohol use may exacerbate older brothers' and sisters' ongoing patterns. The present study examined such possibilities by testing whether the direction and magnitude of sibling influence varied over time. Given the different developmental trajectory of alcohol use as compared to deviant behaviors such as getting into fights, opposition, and theft (Bongers, Koot, Van Der Ende, \& Verhulst, 2004), we examined age-related changes in the links between siblings' behaviors separately for excessive alcohol use and deviant behaviors.

Sibling relationships continue to evolve in early adulthood, and the small body of research on this period suggests two distinct courses for 
their development. On the one hand, positive relational qualities such as warmth and intimacy increase, and negative qualities such as conflict and rivalry decrease during early adulthood (Scharf, Shulman, \& AvigadSpitz, 2005). In turn, more positive relationships may underlie stronger sibling influences, including in the form of greater similarities between siblings' risky behaviors. Consistent with this idea, in a short-term longitudinal study of young adult siblings with alcoholic parents, Trim and colleagues (2006) found older siblings' earlier drinking predicted increases in younger siblings' drinking. Importantly, bidirectional influences were also found among dyads close in age: In dyads with closer age spacing, older siblings drinking predicted younger siblings' drinking behaviors and vice versa.

On the other hand, as their relationship involvement becomes more a matter of choice and opportunity in young adulthood, siblings may have less contact, engage in fewer shared activities (Scharf et al., 2005), and experience greater emotional distance (Stocker et al., 1997; White, 2001). As such, sibling influences may diminish, and similarities between siblings' risk behaviors become less evident. Consistent with the idea of diminishing sibling influences, Poelen et al. (2007) found few associations between the alcohol uses of non-twin siblings in early adulthood. There were, however, significant associations between the alcohol use of both mono- and dizygotic twins, who likely remain closer in young adulthood because of their shared characteristics and experiences.

\section{Current Study}

Based on prior research on sibling influences on risky behavior, we addressed two study goals: (a) to test whether "sibling influences" on deviant behaviors and excessive alcohol use were best characterized as a vertical or as a bidirectional process, and (b) to investigate whether associations between siblings' risk behaviors varied across the course of adolescence and young adulthood. In order to isolate the effects of each sibling's risky behavior on the other's, we controlled for third variables, namely, qualities of the sibling relationship (sibling warmth, conflict), parenting practices (i.e., parental knowledge), and family characteristics (family size, parental education), that might otherwise explain associations between siblings' risky behaviors (East \& Khoo, 2005; Slomkowski et al., 2001; Stattin \& Kerr, 2000). Net of these control variables and based on prior research, we expected to find evidence of vertical sibling influence across adolescence. We also expected, however, that bidirectional influences would emerge in later adolescence, as developmental differences between siblings shrink and their relationships become more egalitarian. Given mixed findings about sibling influences in young adulthood, we did not advance a specific hypothesis about this developmental period. Because previous work suggests that social learning and sibling contagion processes may be stronger among 
same-gender dyads and those close in age (Rowe \& Gulley, 1992; Slomkowski et al., 2001, 2005), we also tested whether associations between siblings' risky behaviors were moderated by the gender composition and age spacing of the dyad.

\section{Method}

Participants. Data came from a 15-year longitudinal study of 201 families that started when first- and second-born youth were in middle childhood. For this study, we used data from five occasions of measurement (spanning the last 10 years of the project), when both siblings' risky behaviors were assessed. Older siblings averaged $16.46(S D=0.79)$ and 28.68 $(S D=0.77)$ years of age and younger siblings averaged $13.88(S D=1.15)$ and $26.06(S D=1.09)$ years of age at the first and last waves of these measurement occasions, respectively. On average, siblings were 2.59 (SD $=0.89$ ) years apart in age. Siblings were almost equally divided by gender (50\% female) and dyad gender constellation (53\% same gender pairs). Retention across the study averaged $80 \%$.

Reflecting the ethnic background of families of the northeastern state where the study was conducted (85\% European American; US Census Bureau, 2000), the sample included almost exclusively European American families. Moreover, reflecting the educational ( $>80 \%$ of adults completed high school) and financial ( $m d n$ income $=\$ 55,714$ for married-couple families) backgrounds of the targeted population (U.S. Census Bureau, 2000), at Time 1 , the average education level was 14.57 years $(S D=2.15$, range $=$ $12-20)$ for mothers and 14.67 years $(S D=2.43$, range $=10-20)$ for fathers (where a score of 12 signified a high school graduate), and the median family income at Time 1 was $\$ 55,000(S D=28,613$, range $=21,000-207,000)$.

Procedures. Families were recruited through letters sent home to fourth and fifth graders in 16 school districts. Interested families returned a postcard to the project and were contacted by phone to confirm whether they met the study criteria, including having two siblings within the targeted age range. Of those families who met the criteria, more than $90 \%$ agreed to participate.

Two data-collection procedures were employed over the course of the study. First, during siblings' adolescence (the first three of the five occasions of measurement used in this study, between about ages 14 and 19), annual home interviews were conducted with mothers, fathers, and both firstborns and secondborns. Family members were interviewed separately, and consent/assent was obtained from each family member prior to the interview. Families were given an honorarium that ranged from $\$ 100$ to $\$ 200$ depending on the study year. Second, during siblings' young adult years (the last two of the five occasions of measurement in this study, about ages 2228), participants, including mothers, fathers, and both siblings, completed both telephone interviews and internet-based surveys. Informed consent 
was audio-recorded during the telephone interviews as well as obtained prior to the internet-based surveys. Young adults received $\$ 100$ and parents received $\$ 25$ for their participation, respectively.

\section{Measures.}

Demographic information. Parents provided family background information including income, education, job prestige, family size, and offspring characteristics such as age, birth order, and gender.

Deviant behaviors. Eight items from Eccles and Barber's (1990) Risky Behavior Scale were used to assess deviant behaviors. At each occasion of measurement, participants used a four-point scale, 1 (never) to 4 (more than 10 times in the past year), to report on their participation in behaviors such as, "do something you knew was dangerous just for the thrill of it," "had contact with the police for something you did or that they thought you did," and "damage public or private property." Across measurement occasions, scores were averaged such that higher scores indicate greater participation in deviant behaviors (see Table 5.1 for descriptive statistics).

Excessive alcohol use. Siblings' excessive alcohol use was indexed via a single item. Across each occasion of measurement, using a scale of 1 (never) to 4 (more than 10 times) participants reported on the frequency with they had "gotten drunk" in the past year (see Table 5.1 for descriptive statistics).

Sibling intimacy. Intimacy in sibling relationships was measured on each occasion with the use of an eight-item measure developed by Blyth and Foster-Clark (1987). Siblings' rated their experiences with their brother/sister on a scale ranging from 1 (not at all) to 5 (very much). Ratings were averaged, with higher scores representing greater intimacy. Across all phases and reporters Cronbach's $\alpha$ ranged from 0.83 to 0.88 .

Sibling conflict. Conflict in the sibling relationship was assessed at each occasion of measurement via a five-item scale from Stocker and McHale's (1992) Sibling Relationship Inventory. Siblings rated their experiences with their brother/sister on a scale ranging from 1 (not at all) to 5 (very much). Ratings were averaged, with higher scores representing greater conflict. Across all phases and reporters Cronbach's $\alpha$ ranged from 0.66 to 0.78 .

Parental knowledge of youth activities. Parents' knowledge of their children's activities was assessed with the use of Stattin and Kerr's (2000) nineitem measure. On a scale ranging from 1 (almost never) to 5 (almost always), mothers and fathers indicated the extent to which they were aware of their children's activities. Parents' completed the measure separately for each sibling, and ratings were averaged across items, with higher scores representing greater knowledge. This measure was only collected in the initial phase of this study and, to reduce the number of control variables, mothers' and fathers' reports were averaged (knowledge of firstborns, $M=4.10, S D=0.46$, $\alpha=0.82$; knowledge of secondborns, $M=4.30, S D=0.38, \alpha=0.80$ ). 


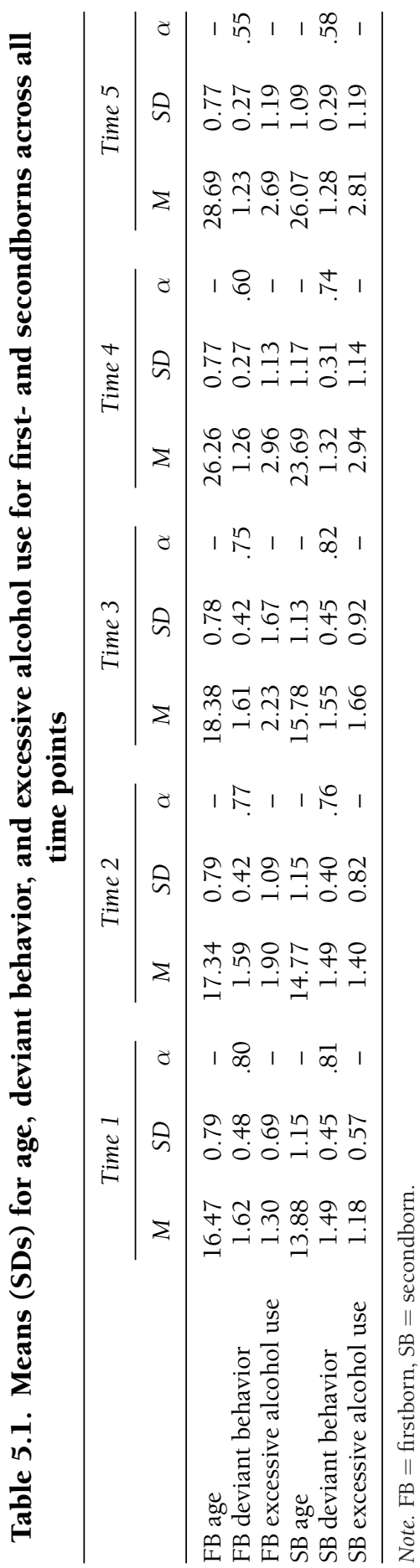




\section{Results}

Analytic Strategy. With the use of Proc Mixed in SAS 9.4, we tested sets of three-level multilevel models (MLM) - time clustered within individuals, individuals within sibling dyads, and sibling dyads within families-for each dependent variable separately. Each set included three steps. In Model 1, we included main effects for linear age (centered at 17.62, the mean age of siblings across all times of measurement) as well as the quadratic function of age to account for the normative developmental trajectory of risky behaviors from adolescence into early adulthood. To assess whether siblings' earlier behaviors were associated with change in their brothers'sisters' subsequent behaviors we included lagged effects of siblings' behaviors for each dependent variable (person-mean centered). If significant, these variables indicate that siblings' earlier behaviors were predictive of change in their brothers'sisters' behaviors in those same domains (i.e., denoting "sibling influence"). Control variables included parents' average education level (centered at the sample mean), family size $(0=$ two siblings only; $1=$ three or more siblings), age difference between siblings (centered at the sample mean), gender composition $(0=$ same gender; $1=$ different gender $)$, gender $(0=$ female; $1=$ male $)$, birth order $(0=$ firstborn; $1=$ secondborn), sibling intimacy (as a time-varying variable, centered at the sample mean), sibling conflict (as a time-varying variable, centered at the sample mean), and parental knowledge (centered at the sample mean). The tests for deviant behavior included siblings' deviant behavior as a predictor, and the test for excessive alcohol use included siblings' excessive alcohol use as a predictor.

To test whether the associations between siblings' behaviors varied as a function of birth order or age, Model 2 included five, two-way interactions: sibling behavior $\times$ birth order, sibling behavior $\times$ linear age, sibling behavior $\times$ quadratic age, linear age $\times$ birth order, and quadratic age $\times$ birth order. A significant sibling behavior $\times$ birth order interaction would signify that the magnitude of sibling influence depended upon birth order (e.g., that older siblings' behaviors were more strongly related to younger siblings' behaviors than vice versa, denoting vertical influence). Sibling behavior $\times$ linear age and sibling behavior $\times$ quadratic age interactions test whether the strength of sibling influence varied over time. To test whether reciprocal influence between siblings was more likely as siblings' entered later adolescence and early adulthood, Model 3 included three-way interactions between sibling behavior, birth order, and age (separately for linear and quadratic age). Initially, we also included four-way interactions to test whether patterns differed by dyad age spacing and/or gender composition. Those interactions were not significant, so they, along with nonsignificant lower-order interactions, were removed (Aiken \& West, 1991).

Models were estimated with the use of full information maximum likelihood (FIML), which uses information from all cases including those with 
Table 5.2. Results of the multi-level model predicting the associations between siblings' deviant behaviors

\begin{tabular}{|c|c|c|c|c|c|c|}
\hline & \multicolumn{2}{|c|}{ Model 1} & \multicolumn{2}{|c|}{ Model 2} & \multicolumn{2}{|c|}{ Model 3} \\
\hline & $\gamma$ & SE & $\gamma$ & $S E$ & $\gamma$ & SE \\
\hline Intercept & $1.18^{* * *}$ & 0.07 & $1.09^{* * *}$ & 0.09 & $1.10^{* * *}$ & 0.09 \\
\hline Linear age & $0.04^{* * *}$ & 0.00 & $0.04^{* * *}$ & 0.01 & $0.09^{* *}$ & 0.03 \\
\hline Quadratic age & $-0.00^{* * *}$ & 0.00 & $-0.00^{*}$ & 0.00 & $-0.01^{* *}$ & 0.00 \\
\hline Parents' education & $-0.02^{*}$ & 0.01 & $-0.02^{*}$ & 0.01 & $-0.02^{*}$ & 0.01 \\
\hline Parents' knowledge & $-0.32^{\text {*** }}$ & 0.04 & $-0.32^{* * *}$ & 0.04 & $-0.32^{* * *}$ & 0.04 \\
\hline Family size & -0.06 & 0.03 & -0.05 & 0.03 & -0.05 & 0.03 \\
\hline Age difference & 0.00 & 0.02 & 0.00 & 0.02 & 0.00 & 0.02 \\
\hline Gender composition & $-0.06^{*}$ & 0.03 & $-0.06^{*}$ & 0.03 & $-0.06^{*}$ & 0.03 \\
\hline Gender & $0.10^{* * *}$ & 0.03 & $0.10^{* * *}$ & 0.03 & $0.10^{* * *}$ & 0.03 \\
\hline Birth order & -0.00 & 0.03 & 0.11 & 0.08 & 0.05 & 0.09 \\
\hline Sibling intimacy & $0.03^{* *}$ & 0.01 & $0.03^{*}$ & 0.01 & $0.03^{* *}$ & 0.01 \\
\hline Sibling conflict & $0.07^{* * *}$ & 0.01 & $0.06^{* * *}$ & 0.01 & $0.06^{* * *}$ & 0.01 \\
\hline Siblings' deviant behaviors (Sib) & $0.08^{* * *}$ & 0.02 & $0.15^{* * *}$ & 0.04 & $0.14^{* * *}$ & 0.04 \\
\hline Sibling $\times$ birth order & & & -0.07 & 0.05 & -0.03 & 0.06 \\
\hline Sibling $\times$ linear age & & & -0.01 & 0.01 & $-0.04^{*}$ & 0.02 \\
\hline Sibling $\times$ quadratic age & & & -0.00 & 0.00 & 0.00 & 0.00 \\
\hline Birth order $\times$ linear age & & & 0.01 & 0.01 & -0.05 & 0.03 \\
\hline Birth order $\times$ quadratic age & & & -0.00 & 0.00 & 0.01 & 0.00 \\
\hline Sibling $\times$ birth order Sibling linear age & & & & & $0.04^{*}$ & 0.02 \\
\hline Sibling $\times$ birth order $\times$ quadratic age & & & & & $-0.01^{*}$ & 0.00 \\
\hline
\end{tabular}

$* p<0.05, * * p<0.01, * * * p<0.001$.

missing values (Arbuckle, 1996; Schafer \& Graham, 2002). Results are organized around the two study goals. Associations between control variables and dependent variables are not discussed, but are presented in the tables.

Deviant Behaviors. Table 5.2 presents the complete results for the tests of sibling influences on deviant behaviors. In Model 1, a positive linear age effect coupled with a significant negative quadratic age effect indicated that deviant behavior peaked in later adolescence and declined in early adulthood. Model 2 revealed no significant two-way interactions, but Model 3 revealed two three-way interactions, a siblings' deviant behavior $\times$ birth order $\times$ linear age and a siblings' deviant behavior $\times$ birth order $\times$ quadratic age effect. Beginning with secondborns' influences, tests of the simple slopes revealed that, net of effects of control variables, secondborn siblings' earlier (lagged) deviant behaviors were positive predictors of firstborns' deviant behaviors at about ages $16(\gamma=0.29, S E=0.06, p<0.001)$ and 18 $(\gamma=0.12, S E=0.04, p<0.01)$, respectively, but secondborns' behaviors in early adulthood did not predict firstborns' deviant behaviors at ages 26 $(\gamma=-0.10, S E=0.06, n s)$ and $28(\gamma=-0.07, S E=0.05, n s)$, respectively (see Figure 5.1). With respect to firstborns' influences, their (lagged) deviant behaviors predicted secondborns' deviant behavior at about age 
Figure 5.1. The association between secondborns' deviant behavior and firstborns' deviant behavior as moderated by age. $* p<0.05$. $* * \boldsymbol{p}<0.01 . * * * \boldsymbol{p}<0.001$

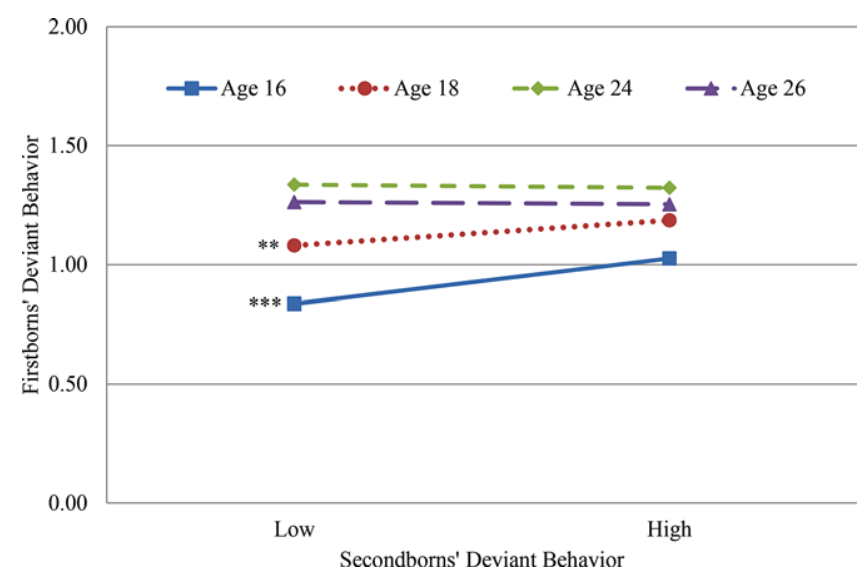

Figure 5.2. The association between firstborns' deviant behavior and seconborns' deviant behavior as moderated by age. $* p<0.05 . * * p<$ 0.01. $* * * \boldsymbol{p}<0.001$

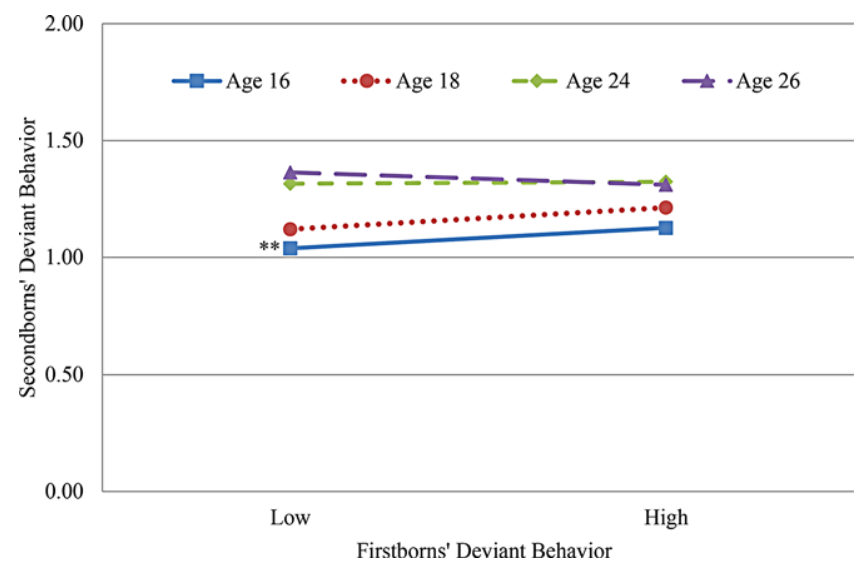

$16(\gamma=0.10, S E=0.03, p<0.01)$, but were unrelated to secondborns' deviant behaviors at ages $18(\gamma=0.07, S E=0.05, n s), 24(\gamma=0.00, S E=$ $0.05, n s)$, and $26(\gamma=-0.02, S E=0.06, n s)$, respectively (see Figure 5.2).

Excessive Alcohol Use. Table 5.3 presents the complete results for sibling influence on excessive alcohol use. The significant positive effect for linear age coupled with the negative quadratic effect indicated that participants "got drunk" more often as they aged, but that this increase leveled off in young adulthood. The significant effect of birth order indicated that, 
Table 5.3. Results of the multi-level model predicting the associations between siblings' excessive alcohol use

\begin{tabular}{|c|c|c|c|c|c|c|}
\hline & \multicolumn{2}{|c|}{ Model 1} & \multicolumn{2}{|c|}{ Model 2} & \multicolumn{2}{|c|}{ Model 3} \\
\hline & $\gamma$ & $S E$ & $\gamma$ & SE & $\gamma$ & SE \\
\hline Intercept & $1.50^{* * *}$ & 19 & $1.37^{* * *}$ & .20 & $1.38^{* * *}$ & .20 \\
\hline Linear age & $0.21^{* * *}$ & 0.01 & $0.28^{* * *}$ & 0.03 & $0.31^{* * *}$ & 0.05 \\
\hline Quadratic age & $-0.01^{* * *}$ & 0.00 & $-0.02^{* * *}$ & 0.00 & $-0.02^{* * *}$ & 0.00 \\
\hline Parents' education & -0.03 & 0.02 & -0.03 & 0.02 & -0.03 & 0.02 \\
\hline Parents' knowledge & $-0.37^{* * *}$ & 0.08 & $-0.37^{* * *}$ & 0.08 & $-0.37^{* * *}$ & 0.08 \\
\hline Family size & $-0.16^{*}$ & 0.07 & $-0.16^{*}$ & 0.07 & $-0.16^{*}$ & 0.07 \\
\hline Age difference & $0.10^{*}$ & 0.04 & $0.10^{* *}$ & 0.04 & $0.10^{*}$ & 0.04 \\
\hline Gender composition & $-0.17^{*}$ & 0.07 & $-0.17^{*}$ & 0.07 & $-0.17^{*}$ & 0.07 \\
\hline Gender & 0.07 & 0.07 & 0.05 & 0.07 & 0.06 & 0.07 \\
\hline Birth order & $0.23^{* * *}$ & 0.07 & $0.42^{* * *}$ & 0.10 & $0.32^{*}$ & 0.14 \\
\hline Sibling intimacy & $0.09^{*}$ & 0.04 & $0.08^{*}$ & 0.04 & $0.08^{*}$ & 0.04 \\
\hline Sibling conflict & 0.04 & 0.04 & 0.05 & 0.04 & 0.05 & 0.04 \\
\hline Siblings' excessive alcohol use (Sib) & $0.11^{* * *}$ & 0.02 & $0.20^{* * *}$ & 0.05 & $0.18^{* * *}$ & 0.05 \\
\hline Sibling $\times$ birth order & & & $-0.11^{*}$ & 0.05 & -0.05 & 0.07 \\
\hline Sibling $\times$ linear age & & & $0.02^{*}$ & 0.01 & 0.01 & 0.03 \\
\hline Sibling $\times$ quadratic age & & & $-0.00^{*}$ & 0.00 & -0.00 & 0.00 \\
\hline Birth order $\times$ linear age & & & $-0.11^{* * *}$ & 0.03 & $-0.14^{* *}$ & 0.05 \\
\hline Birth order $\times$ quadratic age & & & $0.01^{* *}$ & 0.00 & $0.01^{*}$ & 0.01 \\
\hline Sibling $\times$ birth order $\times$ linear age & & & & & 0.02 & 0.03 \\
\hline Sibling $\times$ birth order $\times$ quadratic age & & & & & -0.00 & 0.00 \\
\hline
\end{tabular}

$* p<0.05 . * * p<0.01 . * * * p<0.001$.

at the same chronological age, secondborns drank to excess more often than firstborns. Finally, the significant main effect for siblings' alcohol use indicated that, net of controls, both firstborns' and secondborns' drinking was positively associated with their siblings' excessive alcohol use.

Several two-way interactions emerged in Model 2. A birth order $\times$ siblings' excessive alcohol use effect indicated that, although siblings' alcohol use was positively associated with both firstborns' $(\gamma=0.20, S E=0.05$, $p<0.001)$ and secondborns' use $(\gamma=0.09, S E=0.03, p<0.001)$, the association was stronger for secondborns' predicting firstborns' use. Although this pattern was consistent with bidirectional influences, secondborns' excessive use was a stronger predictor of firstborns' subsequent alcohol use than vice versa. Additionally, siblings' excessive alcohol use $\times$ linear age and siblings' excessive alcohol use $\times$ quadratic age effects suggested that the strength of the association between siblings' use increased from age 16 $(\gamma=0.16, S E=0.05, p<0.001)$ to $18(\gamma=0.20, S E=0.05, p<0.001)$ and 18 to $24(\gamma=0.23, S E=0.04, p<0.001)$, but decreased from 24 to $26(\gamma=0.20, S E=0.04, p<0.001)$. Lastly, birth order $\times$ linear age and birth order $\times$ quadratic age interactions, in combination with follow-up tests, indicated that secondborns "got drunk" more than firstborns at ages 
$16(\gamma=0.62, S E=0.11, p<0.001)$ and $18(\gamma=0.37, S E=0.11, p<$ $0.001)$, but not at ages $24(\gamma=0.07, S E=0.13, n s)$ or $26(\gamma=0.10, S E=$ $0.13, n s)$. There were no significant three-way interactions in Model 3.

\section{Discussion}

A growing body of research has examined sibling influences on youth risky behavior. Our study was designed to contribute to this literature by testing the more typically examined, vertical model of socialization as well as whether younger siblings' risky behaviors also explained differences in older siblings' behaviors in a bidirectional process. Additionally, we extended research by testing whether the strength and direction of sibling influences varied from adolescence into young adulthood. Our analyses took advantage of a unique longitudinal design in which the risky behavior outcomes of firstborn and secondborn siblings were assessed at the same chronological ages-at different points in time. In most prior research, comparisons of sibling influences of older and younger siblings have been made at the same point in time. The confound between age and birth order, however, may mean the differences between older versus younger siblings' influences have been misestimated in prior research. Our analyses were designed to avoid this confound and captured whether the risky behaviors of secondborns, when they were about 2.5 years younger than their siblings, predicted individual differences in firstborns' risky behaviors at about ages $16,18,24$, and 26 , and how the risky behaviors of firstborns, when they were about 2.5 years older than their siblings, explained individual differences in secondborns' risky behaviors at these same ages.

Our hypothesis that firstborns' risky behavior would better explain secondborns' behavior than the reverse was based primarily on studies that have examined the onset of risky behaviors in early adolescence. Our results, however, were inconsistent with this hypothesis, in showing that secondborns' deviant behaviors were somewhat more consistent predictors of firstborns' deviant behaviors (i.e., at ages 16 and 18) than the reverse (only at age 16), and that, although significant for both siblings, secondborns' excessive alcohol use was more strongly related to firstborns' subsequent behaviors than the reverse. Although they have been well articulated in the literature to explain similarities between siblings' risky behaviors, sibling influence processes, such as encouraging and providing exposure to risky behaviors and deviant companions, have rarely been assessed directly (Whiteman, Becerra, \& Killoren, 2009). It may be that by middle adolescence, youth are able to provide these kinds of opportunities for their siblings, regardless of their birth order. Further, because earlier onset is linked to more rapid increases in risky behaviors, younger siblings who engage in deviant behaviors and excessive alcohol use may serve as more extreme models of and provide more opportunities for their siblings to engage in risky behaviors. The age spacing between siblings may also have 
implications for the timing of sibling risky behavior effects. In the current study, for example, normative declines in deviant behavior as youth move into young adulthood, in combination with the fact that many have left the family home by this time and no longer reside with their siblings, mean that firstborns' deviant behavior at age 20 is likely a less relevant and accessible model for secondborns at age 18, whereas secondborns at age 16 may provoke and provide opportunities for the deviant behavior of their 18-year-old, older siblings. Unfortunately, we were unable to test explicitly whether sibling co-residence moderated patterns of influence in early adulthood as only three sibling dyads from this sample lived together during early adulthood. Future research with larger and more diverse samples would benefit from exploring whether co-residence exacerbates patterns of similarity in adulthood.

In addition to assessing potential bidirectional influences, our study also aimed to advance the literatures on sibling relationships and risky behavior by examining the linkages between siblings' behaviors in young adulthood. Findings revealed that, in the case of both firstborns and secondborns, evidence of sibling deviant behavior influences was less apparent in young adulthood than in middle and late adolescence. In contrast, for excessive alcohol use, the effects of sibling use increased until age 24 and then declined to age 26. These patterns mirror normative trajectories of these two domains of risky behaviors in young adulthood: Deviant behaviors such as thrill seeking and theft tend to decline (Bongers et al., 2004), whereas risky alcohol behaviors peak (Chen \& Jacobson, 2012). Taken together, our findings suggest that sibling influences may be more apparent at times when risky behaviors are on the rise. The results pertaining to excessive alcohol use also suggest that siblings continue to serve as important influences on one another's behavior in young adulthood, even as siblings' everyday contact declines and their relationships become more voluntary. As such, future work should investigate the mechanisms of influence during this period. For example, sibling disclosure of alcohol use via talking, texting, or social media posts may be more prevalent and relevant during this period.

Our focus in this study was on sibling influences in the form of similarities between siblings' risky behaviors, but our analyses also illuminated other ways in which siblings may have effects on one another's risky behavior. Our finding that secondborns "got drunk" more frequently than firstborns at ages 16 and 18 is consistent with some prior research in showing documenting earlier onset of risky behavior in laterborn siblings (Rodgers, Rowe, \& Harris, 1992). In contrast to findings for deviant behavior, the birth-order difference in alcohol use was independent of firstborns' level of alcohol use, implying that other mechanisms are at play. Prior research has shown, for example, that parents allow their laterborn children more autonomy than their firstborns (Wray-Lake, Crouter, \& McHale, 2010), meaning that laterborns may have relatively more opportunities 
to engage in risky behaviors. Thus, by paving the way for their younger siblings' greater autonomy, firstborns may indirectly affect their siblings' development.

This study is not without limitations-which imply directions for future research. First, our sample was demographically homogenous and generally low risk, which limits the generalizability of our results. These findings should be replicated in samples that are more diverse in terms of race/ethnicity, family structure, and risky behaviors. Second, our analyses were limited to the period from middle adolescence into young adulthood. Future studies should test whether the directionality of sibling influences varies across childhood and early adolescence and also should extend research to study sibling influences in adulthood. Our findings suggest that there may be differences in sibling influences across domains (deviant behaviors, excessive alcohol use) and that sibling influences may be most evident during periods when behaviors are on the rise, but this hypothesis needs to be tested. Third, we used a single item ("gotten drunk") to assess the frequency of excessive alcohol use in the past year. This item is subjective and requires recall over the past year, which could bias the results. As such, future work would benefit from examining both the frequency and quantity of alcohol use over a shorter period of time (e.g., past 30 days). Fourth, the internal consistency for our measure of deviant behaviors decreased over time, indicating that the items may be less relevant in early adulthood. Fifth, we did not find evidence that sibling influences were stronger for siblings close in age or from same-gender dyads. In general, age spacing in our sample was relatively narrow, thus our sample may have lacked the variability to detect varying patterns. Similarly, our sample included about 100 pairs of same- and mixed-gender siblings. Studies with larger samples may be better able to detect additional patterns of moderation. Finally, our correlational design does not allow for conclusions regarding causality. In general, the term "sibling influences" has been used to describe positive associations between siblings' risky behaviors, but is used in the theoretical, not the empirical sense. That is, research has not established causal relations; instead findings support theory-based predictions of causal relations. Intervention studies aimed at reducing youth risky behavior should empirically evaluate whether and how intervention effects on one sibling spill over to affect the risky behavior of sisters and brothers.

In the face of these limitations, our work contributes to the literatures on sibling influences and young adult adjustment. The study of siblings has been relatively neglected in developmental and family research in comparison to the focus on parental and peer influences (McHale, Updegraff, \& Whiteman, 2012). At the most general level, our findings provide evidence of the centrality of siblings in one another's adjustment and the multiple and complex ways in which sibling influences may ensue. 


\section{References}

Aiken, L. S., \& West, S. G. (1991). Multiple regression: Testing and interpreting interactions. Thousand Oaks, CA: Sage.

Arbuckle, J. L. (1996). Full information estimation in the presence of incomplete data. In G. A. Marcoulides \& R. E. Schumacker (Eds.), Advanced structural equation modeling: Issues and techniques (pp. 243-277). Mahwah, NJ: Erlbaum.

Bank, L., Burraston, B., \& Snyder, J. (2004). Sibling conflict and ineffective parenting as predictors of adolescent boys' antisocial behavior and peer difficulties: Additive and interactional effects. Journal of Research on Adolescence, 14, 99-125. https://doi.org/10.1111/j.1532-7795.2004.01401005.x

Blyth, D. A., \& Foster-Clark, F. S. (1987). Gender differences in perceived intimacy with different members of adolescents' social networks. Sex Roles, 17(11), 689-718. https://doi.org/10.1007/BF00287683

Bongers, I. L., Koot, H. M., Van Der Ende, J., \& Verhulst, F. C. (2004). Developmental trajectories of externalizing behaviors in childhood and adolescence. Child Development, 75(5), 1523-1537. https://doi.org/10.1111/j.1467-8624.2004.00755.x

Brown, S. A., McGue, M., Maggs, J., Schulenberg, J., Hingson, R., Swartzwelder, S., ... Murphy, S. (2008). A developmental perspective on alcohol and youths 16 to 20 years of age. Pediatrics, 121(Supplement 4), S290-S310. https://doi.org/10.1542/peds.2007-2243D

Buhrmester, D. (1992). The developmental courses of sibling and peer relationships. In F. Boer \& J. Dunn (Eds.), Children's sibling relationships: Developmental and clinical issues (pp. 19-40). Hillsdale, NJ: Erlbaum.

Buhrmester, D., \& Furman, W. (1990). Perceptions of sibling relationships during middle childhood and adolescence. Child Development, 61, 1387-1398. https://doi.org/10.1111/j.1467-8624.1990.tb02869

Chen, P., \& Jacobson, K. C. (2012). Developmental trajectories of substance use from early adolescence to young adulthood: Gender and racial/ethnic differences. Journal of Adolescent Health, 50(2), 154-163. https://doi.org/10.1016/j.jadohealth.2011.05.013

Cicirelli, V. G. (1995). Sibling relationships across the life span. New York: Plenum Press.

Conger, R. D., \& Rueter, M. A. (1996). Siblings, parents, and peers: A longitudinal study of social influences in adolescent risk for alcohol use and abuse. In G. H. Brody (Ed.), Sibling relationships: Their causes and consequences (pp. 1-30). Norwood, NJ: Ablex.

Criss, M. M., \& Shaw, D. S. (2005). Sibling relationships as contexts for delinquency training in low-income families. Journal of Family Psychology, 19(4), 592-600. https://doi.org/10.1037/0893-3200.19.4.592

D'Amico, E. J., \& Fromme, K. (1997). Health risk behaviors of adolescent and young adult siblings. Health Psychology, 16(5), 426-432. https://doi.org/10.1037/0278-6133.16.5.426

Defoe, I. N., Keijsers, L., Hawk, S. T., Branje, S., Dubas, J. S., Buist, K., . . . \& Meeus, W. (2013). Siblings versus parents and friends: Longitudinal linkages to adolescent externalizing problems. Journal of Child Psychology and Psychiatry, 54(8), 881-889. https://doi.org/10.1111/jcpp.12049

East, P. L. (1998). Impact of adolescent childbearing on families and younger siblings: Effects that increase younger siblings' risk for early pregnancy. Applied Developmental Science, 2(2), 62-74. https://doi.org/10.1207/s1532480xads0202_1

East, P. L., \& Khoo, S. T. (2005). Longitudinal pathways linking family factors and sibling relationship qualities to adolescent substance use and sexual risk behaviors. Journal of Family Psychology, 19, 571-580. https://doi.org/10.1037/0893-3200.19.4.571

Eccles, J., \& Barber, B. (1990). The risky behavior scale. Unpublished manuscript, University of Michigan. 
Low, S., Shortt, J. W., \& Snyder, J. (2012). Sibling influences on adolescent substance use: The role of modeling, collusion, and conflict. Development and Psychopathology, 24, 287-300. https://doi.org/10.1017/S0954579411000836

McHale, S. M., Bissell, J., \& Kim, J. (2009). Sibling relationship, family, and genetic factors in sibling similarity in sexual risk. Journal of Family Psychology, 23, 562-572. https://doi.org/10.1037/a0014982

McHale, S. M., Updegraff, K. A., \& Whiteman, S. D. (2012). Sibling relationships and influences in childhood and adolescence. Journal of Marriage and Family, 74, 913-930. https://doi.org/10.1111/j.1741-3737.2012.01011.x

McGue, M., \& Iacono, W. G. (2009). Siblings and the socialization of adolescent deviance. An adoption study approach. In K. McCartney \& R. Weinberg (Eds.), Experience and development: A festschrift to honor Sandra W. Scarr (pp. 170-201). London, UK: Taylor \& Francis.

Miller, N., \& Maruyama, G. (1976). Ordinal position and peer popularity. Journal of Personality and Social Psychology, 33, 123-131. https://doi.org/10.1037/0022-3514.33.2.123

Patterson, G. R. (1984). Siblings: Fellow travelers in coercive family processes. In R. J. Blanchard (Ed.), Advances in the study of aggression (pp. 174-214). New York, NY: Academic.

Poelen, E. A., Scholte, R. H., Willemsen, G., Boomsma, D. I., \& Engels, R. C. (2007). Drinking by parents, siblings, and friends as predictors of regular alcohol use in adolescents and young adults: A longitudinal twin-family study. Alcohol and Alcoholism, 42, 362-369. https://doi.org/10.1093/alcalc/agm042

Rende, R., Slomkowski, C., Lloyd-Richardson, E., \& Niaura, R. (2005). Sibling effects on substance use in adolescence: Social contagion and genetic relatedness. Journal of Family Psychology, 19, 611-618. https://doi.org/10.1037/0893-3200.19.4.611

Rodgers, J. L., Rowe, D. C., \& Harris, D. F. (1992). Sibling differences in adolescent sexual behavior: Inferring process models from family composition patterns. Journal of Marriage and the Family, 54, 142-152. https://doi.org/10.2307/353282

Rowe, D. C., \& Gulley, B. L. (1992). Sibling effects on substance use and delinquency. Criminology, 30, 217-234. https://doi.org/10.1111/j.1745-9125.1992.tb01103.x

Samek, D. R., McGue, M., Keyes, M., \& Iacono, W. G. (2015). Sibling facilitation mediates the association between older and younger sibling alcohol use in late adolescence. Journal of Research on Adolescence, 25, 638-651. https://doi.org/10.1111/jora.12154

Schafer, J. L., \& Graham, J. W. (2002). Missing data: Our view of the state of the art. Psychological Methods, 7(2), 147-177. https://doi.org/10.1037/1082-989X.7.2.147

Scharf, M., Shulman, S., \& Avigad-Spitz, L. (2005). Sibling relationships in emerging adulthood and in adolescence. Journal of Adolescent Research, 20, 64-90. https://doi.org/10.1177/07435588404271133

Slomkowski, C., Rende, R., Conger, K. J., Simons, R. L., \& Conger, R. D. (2001). Sisters, brothers, and delinquency: Evaluating social influence during early and middle adolescence. Child Development, 72, 271-283. https://doi.org/10.1111/1467-8624.00278

Slomkowski, C., Rende, R., Novak, S., Lloyd-Richardson, E., \& Niaura, R. (2005). Sibling effects on smoking in adolescence: Evidence for social influence from a genetically informative design. Addiction, 100, 430-438. https://doi.org/10.1111/j.1360-0443.2004.00965

Smetana, J. G., Robinson, J., \& Rote, W. M. (2015). Socialization in adolescence. In J. E. Grusec \& P. D. Hastings (Eds.), Handbook of socialization: Theory and research (pp. 60-84). New York, NY: Guilford.

Staff, J., Schulenberg, J. E., Maslowsky, J., Bachman, J. G., O'Malley, P. M., Maggs, J. L., \& Johnston, L. D. (2010). Substance use changes and social role transitions: Proximal developmental effects on ongoing trajectories from late adoles- 
cence through early adulthood. Development and Psychopathology, 22, 917-932. https://doi.org/10.1017/S09545794100000544

Stattin, H., \& Kerr, M. (2000). Parental monitoring: A reinterpretation. Child Development, 71, 1072-1085. https://doi.org/10.1111/1467-8624.00210

Stocker, C. M., Lanthier, R. P., \& Furman, W. (1997). Sibling relationships in early adulthood. Journal of Family Psychology, 11, 210-221. https://doi.org/10.1037/0893-3200.11.2.210

Stocker, C., \& McHale, S. M. (1992). The nature and family correlates of preadolescents' perceptions of their sibling relationships. Journal of Social and Personal Relationships, 9, 179-195. https://doi.org/10.1177/0265407592092002

Trim, R. S., Leuthe, E., \& Chassin, L. (2006). Sibling influence on alcohol use in a young adult, high-risk sample. Journal of Studies on Alcohol and Drugs, 67, 391-398. https://doi.org/10.15288/jsa/2006.67.391

Tucker, C. J., Barber, B. L., \& Eccles, J. S. (1997). Advice about life plans and personal problems in late adolescent sibling relationships. Journal of Youth and Adolescence, 26, 63-76. https://doi.org/10.1023/A:1024540228946

Tucker, C. J., \& Updegraff, K. (2009). The relative contributions of parents and siblings to child and adolescent development. New Directions for Child and Adolescent Development, 126, 13-28. https://doi.org/10.1002/cd.254

U.S. Census Bureau. (2000). Profile of general demographic characteristics: 2000. Retrieved from http://factfinder.census.gov/faces/tableservices/jsf/pages/ productview.xhtml? src $=\mathrm{CF}$

White, L. (2001). Sibling relationships over the life course: A panel analysis. Journal of Marriage and Family, 63, 555-568. https://doi.org/10.1111/j.1741-3737.2001.00555.x

Whiteman, S. D., Becerra, J. M., \& Killoren, S. (2009). Mechanisms of sibling socialization in normative family development. New Directions for Child and Adolescent Development, 126, 29-43. https://doi.org/10.1002/cd.255

Whiteman, S. D., Jensen, A. C., \& Maggs, J. L. (2013). Similarities in adolescent siblings' substance use: Testing competing pathways of influence. Journal of Studies on Alcohol and Drugs, 74, 104-113. https://doi.org/10.15288/jsad.2013.74.104

Whiteman, S. D., Jensen, A. C., Mustillo, S. A., \& Maggs, J. L. (2016). Understanding sibling influence on adolescents' alcohol use: Social and cognitive pathways. Addictive Behaviors, 53, 1-6. https://doi.org/10.1016/j.addbeh.2015.09.007

Whiteman, S. D., Zeiders, K. H., Killoren, S. E., Rodriguez, S. A., \& Updegraff, K. A. (2014). Sibling influence on Mexican-origin adolescents' deviant and sexual risk behaviors: The role of sibling modeling. Journal of Adolescent Health, 54, 587-592. https://doi.org/10.1016/j/jadohealth.2013.10.004

Windle, M. (2000). Parental, sibling, and peer influences on adolescent substance use and alcohol problems. Applied Developmental Science, 4, 98-110. https://doi.org/10.1207/S1532480XADS0402_5

Wray-Lake, L., Crouter, A. C., \& McHale, S. M. (2010). Developmental patterns in decision-making autonomy across middle childhood and adolescence: European American parents' perspectives. Child Development, 81, 636-651. https://doi.org/10.1111/j.1467-8624.2009.01420.x

Shawn D. Whiteman, Ph.D., is an Associate Professor in the Department of Family, Consumer, and Human Development at Utah State University. Broadly, his research focuses on the connections between family socialization processes and youth's adjustment. He is specifically interested in the direct and indirect processes through which siblings shape each other's health-risk behaviors during adolescence and early adulthood. 
Alexander C. Jensen, Ph.D., is an Assistant Professor in the School of family Life at Brigham Young University. His research focuses on the mechanisms through which siblings influence one another's development during adolescence and adulthood, with a primary focus on the role of parental differential treatment.

Susan M. McHale, Ph.D., is the director of the Social Science Research Institute and a Distinguished Professor of Human Development and Family Studies at the Pennsylvania State University. Her major research interests focus on children's and adolescents' family roles, relationships, and activities with a particular emphasis on gendered family dynamics and youth's sibling relationship experiences. 